\title{
La obediencia como consejo evangélico en la vida consagrada
}

\author{
Ma ASCENSIÓN MATÁS GARCÍA \\ Universidad Católica San Antonio de Murcia (España) \\ mamatas@ucam.edu
}

\begin{abstract}
Resumen
A través de este artículo se llegará a la conclusión de que la obediencia es una expresión de la dialéctica entre la encarnación de Cristo y su kenosis, superando la provisionalidad de las realidades terrenas y consagrando a Dios la facultad de disponer de la propia vida. Pero este caminar entre la vida y la muerte, encuentra su punto culminante en el misterio pascual de Jesucristo, el cual contribuye a la glorificación de Dios en el hombre, haciendo de la experiencia de Dios en Jesucristo, el proyecto fundamental de la vida. El hombre participa de este misterio mediante la contemplación y lo extiende hacia fuera gracias a la predicación. Se pondrá así de relieve la dimensión pneumatológica y eclesial de la obediencia, que parte de la imagen de un hombre apasionado y entusiasta del sueño de Dios sobre la humanidad, revelado y realizado en Jesús, por la fuerza del Espíritu de amor.
\end{abstract}

Palabras clave: obediencia, consejo evangélico, autotrascendencia, carisma, vocación, misión, voluntad.

\section{Obedience as an evangelical counsel in consecrated life}

\begin{abstract}
Through this article you will come to the conclusion that obedience is an expression of the dialectic between the incarnation of Christ and his 'kenosis', surpassing the impermanence of earthly realities and consecrating to God the faculty to dispose of one's own live. But this journey between life and death, finds its culmination in the Paschal Mystery of Jesus Christ, which contributes to the glorification of God in man, making the experience of God in Jesus Christ, the fundamental project of life. The Man participates in this mystery, through contemplation, and extends it out through the preaching. In this way, it will express the pneumatologic and ecclesial dimension of obedience, which part of the image of a passionate and enthusiastic man of God's dream for humanity, revealed and realized in Jesus, by the power of the Spirit of love.
\end{abstract}

Key words: obedience, self-transcendence, charisma, vocation, mission, will.

Licenciada y doctora en Teología de la vida consagrada en el Instituto de Teología de la Vida Consacrada, Claretianum, de Roma, perteneciente a la Pontificia Universidad Lateranense. Ha escrito artículos acerca de diversas temáticas teológicas sobre la vida religiosa, así como sobre Misionología, Teología fundamental e investigación histórica. Autora del libro Madre Josefa Alzúa: un cimiento para la Congregación de Religiosas misioneras de Santo Domingo (2009). 


\section{La obediencia: una respuesta a la misión de autotrascendencia del ser humano}

La obediencia es la expresión vital de la dimensión trascendental del ser humano, quien a través de la razón y la fe, se adentra en un proceso de profundización e identificación de su ser, que encuentra su culmen en la unión con Dios.

\subsection{La aceptación de la propia condición de criatura}

El hombre religioso vive bajo la certeza de haber sido llamado a la existencia por Dios, quien establece una peculiar comunicación con la humanidad a lo largo de la historia. Realidad que se hace visible mediante la creación del hombre, se desarrolla gracias a su vocación y se especifica por su misión. Aquí se insertan los misterios absolutos de la vida, que sólo se dan en la comunicación de Dios con la profundidad de la existencia humana, denominada gracia, y con la historia, que como ya veremos, tiende hacia Jesucristo. Son las coordenadas desde las que el hombre se esfuerza por hallar su propio centro, al que poder acomodarse, sin destruir su intrínseca finitud. Convirtiendo no a la razón, sino al espíritu, en la facultad para percibir lo incomprensible en cuanto tal, y asumir el misterio (Feuerbach, 1975: 55).

La estructura religiosa del hombre brota de una dimensión original de su existencia humana, cuya apertura a la trascendencia corresponde a una automanifestación y autocomunicación de Dios. No sólo Dios es el tú del hombre, sino que el hombre es el tú de Dios, que encuentra en la búsqueda de su felicidad, una huella de Dios en sí mismo. Frente a esta inquietante necesidad de salir de sí mismo, el hombre se halla enmarcado por una infinitud. Ésta penetra su acción cotidiana, manifestando paradójicamente la finitud de un ser, que se experimenta como ser que trasciende y retrocede cada vez más lejos cuantas más respuestas es capaz de darse.

Por medio de la razón, el hombre puede conocer a Dios, a partir de sus obras. Pero existe otro tipo de conocimiento al que el hombre no puede acceder con sus fuerzas: el de la revelación divina (Rahner, 1979: 51). A través de ella, Dios se da al hombre y revela plenamente su designio de bondad preestablecido en Cristo, a favor de todos los hombres. Como ya veremos, el presente escatológico de Jesús remite al futuro histórico y éste se anticipa en aquel, de tal forma que la escatología se hace historia y la historia se vuelve escatológica. Pero el verdadero misterio, aún después de revelado, conserva su innata trascendencia, superando así el alcance y la capacidad de comprensión 
por la razón. Al mismo tiempo, conjuga la eternidad con la historicidad, lo irrevocable con lo siempre actual y lo personal con lo comunitario.

Dios se revela en la conciencia del hombre y manifiesta en la historia de la humanidad, kairós de la salvación, su designio sobre el mundo, es decir, lo que desde su eternidad, pensó y proyectó sobre el mismo. Este último aparece interpretado no como una magnitud estática, sino como el tiempo favorable para construir la propia historia, como historia de salvación. Las diversas interpretaciones respecto a dicha actuación divina, generan diversas imágenes de Dios, que resultan fundamentales para nuestro tema y que, básicamente, pueden resumirse en: el Dios sin historia, el Dios entronizado por la historia y en la historia, y en la historia de Dios. Esta última, orientada hacia la promesa del mundo nuevo, se halla integrada por el despliegue de la historia personal de cada hombre, connotada por su privacidad, especificidad e intercomunicación con las historias del resto de hombres. En particular, la historia personal es una sucesión de hechos pasados, presentes y futuros, que se convierte en la síntesis de toda la historia de la salvación, constituida por diversos modelos de comprensión y distintas imágenes de Dios y de su acción en la historia de cada hombre (Fernández, 2005: 269-270).

Precisamente, la obediencia fundamental a Dios es en primer lugar una llamada a aceptar la propia condición de criatura, es decir, a recibir la misma vida como don. Del mismo modo, conlleva la admisión de una serie de acontecimientos y personas, tiempos y lugares, que constituyen la historia personal, respecto a los cuales el hombre no ha tenido posibilidad de opción. El hombre ni procede de sí mismo, ni ha elegido libremente su existencia, sino que se encuentra con ella, como un dato irrefutable, que constituye tanto un privilegio, como una obligación y una necesidad. Porque existir humanamente no sólo es pasión de ser, sino también creación de un ser, que tiene que ir haciéndose ininterrumpidamente, porque nunca puede considerarse del todo terminado (Alonso, 1998: 28).

De este modo, la obediencia es histórica, porque parte de Dios, pero termina en la tierra, donde la persona está llamada a construir su respuesta al proyecto de Dios, dándose a sí misma unos fines intermedios, que le conducen o le apartan del fin último. Por ser histórica la obediencia es también un acto de crisis y una fuerte invitación a la decisión. La crisis es una fase desestructurante y de liberación, que en cierto modo destruye lo que el hombre es, para poder elaborar su nueva identidad. Es una oportunidad de educación y crecimiento, por la que el sujeto deja de ser un personaje cualquiera para convertirse en una persona con un nombre, es decir, con una misión bien definida en el universo. Todos los interrogantes acerca de la misión 
del ser humano, reciben una respuesta genérica, dentro de este planteamiento antropológico, que abarca a la misión de la persona, como un autotrascenderse aplicado a su potencia obediencial o deseo de comunión con Dios y, a través de Él, con toda la realidad.

El hombre es una realidad unitaria, compuesta de interioridad y comunión al mismo tiempo, cuya condición humana es la incertidumbre sustancial de quien está siempre en peligro de no ser él mismo o de dejar de ser el que es, es decir, de traicionar su propia identidad. Su destino depende de la certeza de su inseguridad y de su aspiración radical a la autorrealización, es decir, a dar cumplimiento a esa incitante profecía que cada uno es para sí mismo y que responde a sus más íntimos anhelos (Lisboa M. De Oliveira, 2003: 215). Se trasciende a sí mismo y a todo lo creado y se abre al infinito, al que identifica con una persona libre que le llama y que se le entrega en un acto gratuito de amor. Ésta, que es su máxima razón de ser, se manifiesta tanto en su movimiento interior de autotrascendencia, como en el movimiento de los pueblos, cuyo destino oculto e inquietante, se convierte en añoranza, deseo y súplica de gracia. Un «Maranatha», que deja al descubierto los límites y la incapacidad para realizar aquello que el hombre sueña (De Sahagún Lucas, 1996: 17).

La plenitud y perfección del hombre dependen de su ordenación profunda al misterio permanente de Dios, al que tiende necesariamente, desde su realidad del ser de la ilimitada trascendencia. Por eso, la razón más alta de la dignidad humana, consiste en la llamada del hombre a la unión con Dios. Sólo cuando reconoce libremente la veracidad de esta afirmación y se confía plenamente a su Creador, alcanza la plenitud de su existencia, la cual surge como efecto del amor y es invitada a desarrollarse en el mismo. Precisamente, la misión de la vida religiosa, radica en su identificación con esta vivencia de trascendencia y contingencia propia, constituida desde una experiencia trascendental personal y comunitaria. Utiliza la dimensión humana y corpórea de la propia vida, para realizar sensiblemente en este mundo las realidades futuras y la aspiración hacia la unión con el único Esposo. Para vivir con Cristo, compartir su vida, estar con Él, como nos dirá Mc 3,14, y poder compartir su misión apostólica.

Se trata de la vocación religiosa, cuyo primer momento de identificación, constituye la forma original de la obediencia, que adentra al propio ser en su proceso histórico de verificación (Rey García Paredes, 2002: 271-272). En definitiva, la respuesta a ese proceso de fundamentación del ser, desarrollado a través de un llamamiento personal dirigido a la conciencia más profunda del individuo. De este modo, lo incita a la autotrascendencia y a una entrega libre, mediante las cuales se va expresando toda su especificidad como persona. Ésta, más allá de la 
propia ratificación de su ser, busca el alcance del propio yo ideal, anticipando su totalidad, mediante el descubrimiento del amor, como la ley inscrita por Dios en su corazón, en cuya obediencia se halla la dignidad humana.

Se trata de una exigencia ontológica de apertura del hombre hacia su connatural trascendencia, que supera los momentos concretos de espacio y tiempo de su historia, se extiende a toda su existencia y afecta radicalmente a todas sus dimensiones. Se opone así al posible dualismo entre espíritu y materia, eternidad y tiempo, divinidad y humanidad, sobrenaturalidad y naturalidad. En concreto, el religioso convierte su vida en una forma histórica de obediencia al Evangelio, por la que accede al misterio de la obediencia de Jesús a su Padre. Como ya veremos, esta última se transforma en la expresión de su misma identidad como religioso. Éste, como todo hombre, alcanza su dignidad tanto en su procedencia, de ser creado a imagen de Dios, como en su destino de comunión con Él, en cuanto llamado a conocerle y amarle. De este modo, obedeciendo a Dios es fiel a sí mismo, coherente con su ser de creyente y se hace más auténtico, más verdadero.

\subsection{La llamada a unirse al Creador}

Estas afirmaciones ayudan a comprender tanto la forma de interpretar la obediencia del religioso y de la comunidad religiosa, dentro de la misión de la humanidad, como el influjo que ejerce en ésta y las características antropológicas que configuran la obediencia del hombre en cada una de ellas. Porque la obediencia al designio universal de Dios no se vive de una manera desencarnada, fuera del tiempo y de la historia, sino que adquiere forma en la existencia de personas concretas, insertas en un medio determinado. El distanciarse de la humanidad, significa traicionar la fe cristiana, huyendo de la lógica del misterio de la encarnación de Jesús y de la esencia de su discipulado y olvidarse de que el religioso, como parte de la Iglesia, no sólo ofrece algo al mundo, sino que también recibe de él.

Por lo tanto, la obediencia del religioso no conlleva su huida del mundo, sino que lo interpela a abrirse a la revelación del designio divino sobre la creación, hasta descubrir la dimensión constituyente de la realidad. Pero todo lo creado, es llamado a la divina glorificación, es decir, a volverse hacia su Artífice, descubriendo la sublimidad de su propio origen y comprendiendo su propia grandeza, en cuanto salido de la mano de Dios.

El religioso, que como todo hombre se halla en camino hacia él mismo, contempla su existencia como radical contingencia. Parte de 
aquella realidad misteriosa que le hace ser y tomar conciencia vital de que no es un puro hecho sin sentido y de que debe retornar ontológica y libremente a su fundamento y fuente del ser (Juan Pablo II, 1984: n. 4). De este modo, su vida se convierte en una mediación de Dios, que armoniza la esencia y existencia humanas y transforma la vocación, consagración y misión en las facetas de una misma realidad, que responde en plenitud al proyecto del Creador (Sagrada Congregación para los Religiosos e Institutos seculares, 1983: n. 23). Porque el hombre, hecho a imagen divina, se transforma en una forma concreta con la que Dios se da, actuando el mandato recibido de colaborar así en la tarea creadora.

La búsqueda religiosa se convierte así en uno de los signos más identificativos del ser humano, del que depende el sentido de su vida y, en definitiva, la riqueza de su yo, el cual se afirma en su relación con los demás y en un grado supremo con su Creador. Mediante un continuo movimiento, la persona humana alcanza al tú absoluto, soporte de su origen y su meta, cuya adhesión expresa a través de la fe. Ésta no significa un mero reconocimiento o aceptación intelectual, sino una entrega, que hace del hombre formal y constitutivamente experiencia de Dios, quien posee una forma universal de ser experiencial para todo hombre.

De todo lo visto en este epígrafe, podemos afirmar que el hombre es un ser llamado a la trascendencia, en el cual el reino de la razón y el camino de la libertad, necesitan ser sazonados por la fe, para conducir al hombre a su plenitud, que sólo se alcanza a través de la unión directa con Dios. Las relaciones sociales y sus diversas manifestaciones se convierten en un reflejo de este ser, que se siente impulsado a salir de sí mismo. Porque padece la imperfección de su existencia histórica, a través del dolor y de la degustación de una felicidad terrena, que hace entrever su caducidad y su condición de espejo nítido de lo que es en sí misma la auténtica felicidad.

Elevado al mundo sobrenatural posee una nueva facultad de conocimiento, que se llama fe, y una capacidad de amor denominada caridad, que le llevan a conocer y amar de una manera divina, aunque condicionada por su situación actual. La consideración consciente o inconsciente de su imperfección, convierten al hombre en un empedernido buscador de la porción que podrá colmar aquel espacio vacío, que parece formar parte de su ser, como realidad histórica. En definitiva, todo parece hablar de unión, pero ¿a quién o a qué? ¿A cualquier realidad terrena, que seduce su mirada bajo el colorido de una máscara, que esconde tras de sí la mortecina caducidad que denota toda hechura humana? ¿Será acaso capaz de encontrar respuesta en el 
endiosamiento de una razón o de un sentimiento, que lo convierte en aquel racionalista o romántico, que espera saciar su imperfección, sin salir de sí mismo?

Por medio de la personificación que va obteniendo por la obediencia, el religioso glorifica a Dios, contempla a su vocación como misión y expresa su adhesión a esta realidad a través de la aceptación intelectual de la misma y la entrega a Dios.

\section{La existencia cristiana como obediencia a Dios y a su mediador Jesucristo}

A través de su carisma específico, el religioso se transforma en una prolongación histórica y activa de Jesucristo, el Siervo obediente al Padre, quien hizo de su renuncia, una apertura a la vida verdadera, en donde el hombre se renueva.

\subsection{La recapitulación de la creación en Cristo}

Resulta fundamental señalar que el Concilio Vaticano II presenta a la Iglesia como un misterio de salvación sobrenatural, que prolonga histórica, temporal y actualmente el plan salvador del Padre al establecer una comunión de vida con Cristo. Se convierte en signo sacramental de su invisibilidad y en un misterio de obediencia, aunando a sus miembros bajo una misma profesión de fe, recepción de sacramentos y obediencia a la autoridad jerárquica.

En Cristo, lo histórico era signo de lo teológico y, lo humano, signo, expresión e instrumento vivo de su divinidad, hasta convertirse en sacramento de Dios. La Iglesia es sacramento de Cristo, que a través de su peregrinación por este mundo, continúa y explicita históricamente su presencia visible, manifestando con rotundidad la vida cristiforme, como la ley principal de la vida de todo creyente. De este modo, la existencia cristiana se identifica con una larga paciencia, alentada y sostenida por la esperanza, cierta y cada día renovada, del encuentro definitivo con Cristo. A su vez, la santificación, es una auténtica cristificación, es decir, un proceso histórico de transformación e identificación con Cristo.

En efecto, situándose al final del plano de la salvación, en el momento de su plena consumación, es como puede entenderse su origen, su desarrollo total, y lo que determina su movimiento interno. El designio del Padre es recapitular todas las cosas en Cristo (Concilio Vaticano II, 1965b: n. 45), origen y sostén, que lo unifica todo, frente a 
todas las mutaciones, y hacia el que todo devenir histórico tiende como a su fin supremo y causa final.

La historia se presenta como designio unificado, que encuentra su centro en la encarnación, continuación y recapitulación de la creación entera, por obra de Aquel mediante el cual ha visto la existencia (Fernández, 1995: 251-252). El futuro absoluto es Dios mismo, quien en absoluta donación, abraza a todo, como consumación y afirmación del mundo y del hombre. A través del don de la humanidad de Jesús, Dios se revela plenamente a la humanidad, y se acerca a ella, convirtiendo al tiempo en su dimensión divina de eternidad y señalando posibilidades y metas a su devenir.

La historia de la salvación no es una historia cualquiera, ni tampoco la historia más sublime de todas. Es simplemente la historia, es decir, el conjunto de acontecimientos por los cuales Dios realiza su designio inefable de creación y salvación del mundo y de la humanidad. Gracias a esa intervención personal de Dios en el tiempo de los hombres, la historia humana cesa de ser por sí misma una sucesión de hechos, a los que la muerte pondría fin paradójicamente, para adquirir sentido, desde su orientación al acontecimiento central: Jesucristo. El misterio de la epifanía, manifestación, y el misterio de pascua, paso salvador, revelan al Dios que se da salvando y salva dándose, e invitan a entrar en el misterio de Cristo, adhiriéndose vitalmente a su Persona.

El hombre sólo puede entenderse desde esta única clave que le ha sido dada histórica y axiológicamente, la cual le revela su estado original de perfección a imagen de Dios y, al mismo tiempo, se convierte a Cristo, en el interlocutor contemporáneo para cada creyente y para el cuerpo eclesial (Concilio Vaticano II, 1964: n. 10). El hombre está llamado a abrirse a la plenitud, a través de una fe en Jesús, que viene interpretada no como una conclusión de los conocimientos históricos, sino como una decisión libre, basada en ellos, la cual comporta el riesgo de la obediencia, es decir, de existir y de crecer. Así, la existencia humana se convierte en un proceso de transformación en Jesucristo, a través de una metamorfosis, que otorga un nuevo sentido al desarrollo vital (Juan Pablo II, 1996: n. 109). Como dice Pablo en Gal 2,20: «ya no vivo yo, sino que Cristo vive en mí. Esta vida en la carne, la vivo en la fe del Hijo de Dios que me amó y se entregó a sí mismo por mí».

La contemporaneidad con Jesucristo, se interpreta no desde el sentido inmediato de la acepción histórica de la palabra, sino como la condición de la fe para cada generación, que transforma su seguimiento en mistagogía. De este modo, la existencia cristiana se define como una obediencia radical a Dios y su mediador por excelencia, Jesucristo, quien a través de su obediencia al Padre, expresión máxima de su amor, nos 
hace pasar de la muerte a la vida y nos hace vivir en Él (Rom 5,19). La obediencia religiosa no debe presentarse como el lugar y el modelo de la obediencia al Evangelio, sino que es una forma de expresarla y un camino para acceder a ella. La muerte de Jesús se convierte en el modelo y la obediencia es un modo de cristología existencial, en cuanto significa hacer en la vida, un ejercicio de preparación para acoger su destino. La obediencia no es la fuente (1 Jn 2,17), sino la condición fecunda de nuestra salvación, el camino que nos lleva a la verdadera vida (Ruiz de la Peña, 1991: 265).

En este sentido, la fe y la obediencia constituyen una pareja de conceptos inseparables, que se vivifican el uno al otro y son asumidos por la caridad, indicando que no existe resurrección sin muerte. Esta realidad puede resonar con una cierta dureza en nuestro presente, fuertemente habituado a la conquista de la competitividad y el éxito y al rechazo espontaneo de todo aquello que suena a mediocridad y donde las huellas persistentes del carpe diem no conciben el carácter de provisionalidad de las realidades terrenas.

Se inserta aquí la esperanza como la actitud positiva propia de una antropología de fe. No sólo como iluminación y adecuación al presente, sino también como una discontinuidad, cuyo recorrido remite al misterio de Cristo y a aquel futuro en el que Dios será todo en todos. De este modo, la fe se presenta como una garantía de identidad, aún en medio de la realización necesaria de ciertas modificaciones. La relación entre la escatología y la cristología señala en Cristo la esperanza, como hecho concreto en el que se proclama y se realiza el futuro del hombre. Se contrapone a la visión ilusoria del progreso histórico, como única meta de la vida humana, que origina en la modernidad, una cierta desesperanza, ante el aparente derrumbamiento de las grandes utopías y la pérdida de un hacia dónde, que dé sentido al camino de la humanidad.

Del mismo modo, esta existencia cristiforme se plasma en los consagrados como una adhesión total a Cristo, manifestando una tensión global, que anuncia en cierto modo el futuro. De tal forma, la vida religiosa se transforma en una forma de existencia cristiana que se proclama memoria viviente del modo de existir y de actuar de Jesús y comulga en su misterio de obediencia al Padre, a través de la dimensión cristológica y soteriológica (Juan Pablo II, 1996: n. 22). Sin olvidar que obedecer es la esencia del ser de Jesús, hasta el punto de que en su existencia, sólo buscó hacer la voluntad de su Padre (Boisvert, 1989: 17). Su desobediencia en la obediencia, condenó la tradición de los antiguos y la actitud de los que aferrándose a las tradiciones humanas dejaron a un lado el mandamiento de Dios (Mc 7,8), pero al mismo tiempo no derogó, sino que perfeccionó la ley (Mt 23). 
En concreto, la vida religiosa es una expresión de la esencia de la Iglesia, en la que cada uno de sus miembros participa en la dialéctica, entre el lenguaje afirmante de la encarnación de Cristo y el silencio místico de su kenosis. De este modo, transforma la obediencia en la oportunidad de participar más activamente en la vocación eclesial, que es la de recordar y servir el designio de Dios sobre los hombres, tal como anuncian las Escrituras y como se desprende de una atenta lectura de la acción providencial de Dios en la historia. En Cristo esta pedagogía alcanza su meta, porque no se limita a hablar en nombre de Dios, sino que es Dios mismo quien habla por medio del Verbo. De manera que no sólo el hombre busca a Dios, sino que Dios viene en Persona a hablar de sí al hombre y a mostrarle el camino por el cual es posible alcanzarlo (Juan Pablo II, 2001: n. 7).

\subsection{El carisma: una lectura particular del misterio de Cristo}

La centralidad del misterio pascual, como acto de obediencia y amor al Padre y de entrega, mediante el cual Cristo dona voluntaria y totalmente su vida, conduce al religioso a llegar a vivir en sí mismo la significación de plenitud lograda. En efecto, el fundamento evangélico de la vida consagrada se halla en la relación especial que Jesús estableció con algunos de sus discípulos, durante su vida terrena, invitándoles no sólo a acoger el reino de Dios, sino a poner la propia existencia al servicio del mismo, compartiendo su experiencia de virgen, pobre y obediente (Juan Pablo II, 1996: n. 14).

En términos generales, se puede afirmar que seguir a Jesucristo es ser llamados personalmente por Él (vocación), para vivir con Él y con sus seguidores (comunión), viviendo como Él (consagración) y perpetuando su mismo quehacer en el mundo (misión) (Juan Pablo II, 1996: nn. 17-18). Este género di vida viene considerado como el modo más radical de vivir el Evangelio en esta tierra, el cual puede ser calificado de divino, porque es abrazado por el Hombre-Dios, como expresión de su relación de Hijo-Unigénito con el Padre y con el Espíritu (Juan Pablo II, 1996: n. 18). Dicho seguimiento es el camino de realización de la tarea primordial de la vida religiosa, dentro de la misión de la Iglesia, consistente en contribuir a la expansión de la glorificación de Dios en el hombre (Juan Pablo II, 1994: n. 6). Así se lleva a su término su llamada a retornar a su fundamento del ser y a expresar la grandilocuencia del mismo (González de Cardedal, 1975: 372).

Esta diafanía de la gloria de Dios, se realiza por medio de una consagración ontológica del religioso, consistente en asumir en su totalidad todas sus fuerzas de amar, el deseo de poseer y la facultad de 
disponer de la propia vida. De este modo manifiesta abiertamente la epifanía de todas las perfecciones divinas, visibilizadas en el mundo, y testifica su glorificación, en el Señor Resucitado. Para ello, el consagrado contempla al Transfigurado, imagen de Dios invisible y resplandor de la gloria del Padre, quien amorosamente atrae hacia sí a una criatura para una misión especial. Se percibe la profundidad de un amor eterno que toca y seduce las raíces del ser, hasta desear identificarse con Él, asumiendo sus sentimientos y su forma de vida y consagrando todo, presente y futuro, en sus manos, como un programa válido para todas las personas y tiempos (Juan Pablo II, 1996: nn. 17-18).

De esta manera, el hombre se convierte en un nuevo ser, a modo de nueva creación. Conquista su plenitud, esforzándose por asociarse a la obra de la redención (Concilio Vaticano II, 1965: n. 22) y a la dilatación del Reino de Dios, en el que se unen el principio y el fin de la historia de la salvación, la gloria de Dios y la salvación del hombre, y se explica el puesto singular de Cristo. Pero dado lo insondable e inagotable que resulta el misterio de Cristo, la vida religiosa penetra en el mismo, a través de lecturas particulares que versan respectivamente sobre aspectos determinados del mismo (Ciardi, 1982: 288). Éstos se concretizan a través de los diversos carismas, que afirman la existencia de un cambio original dentro del seguimiento común, inaugurando una nueva vía de santidad, que posibilita la plena entrega de sí mismo a Dios por medio de Cristo. Se convierten en el ángulo visual para la penetración de Cristo en su totalidad y del plan divino sobre la creación y sobre la humanidad. En el criterio que guía e ilumina la modalidad específica con la que cada familia religiosa desempeña su servicio específico.

De aquí se desprende la consideración del carisma como una fotografía viviente de una de las múltiples facetas de Cristo, que nos remite al resto. No sólo manifiesta en su período de gestación, su condición de nueva vía de conformación al mismo y su necesidad de dar respuesta a las necesidades de su época. Por el contrario, su vitalidad perdura siempre, encontrando nuevas formas de expresión o renovando las ya existentes, según las urgencias de cada período histórico, conservando aquella dimensión cristológica que le llevó a nacer y a comprometerse por ser un fiel recordatorio de la misma.

El carisma es un estilo de vida que da forma y contorno a la vida de cada miembro de un instituto, hasta formar un solo cuerpo, enriquecido bajo la diversidad de dones, que convergen hacia un mismo punto. Es la encarnación viviente de una de las múltiples facetas que configuran la persona del Jesús encarnado, muerto y resucitado, que despierta en el hombre el deseo de unirse a Él, dejándose seducir y arrastrar por las 
redes del enamoramiento. Es un barómetro que mide la separación del hombre respecto a su origen y meta.

La unión de todos los carismas, nos va mostrando una imagen más diáfana del Cristo total, referencia esencial y constitutiva que convierte a la existencia del religioso en una epifanía, que revela a Cristo con un estilo peculiar. Se establecen así diferenciaciones entre los diversos institutos religiosos, caracterizadas por su condición de signo, que llama la atención, suscita interrogantes y provoca admiración. Así lo corroboran las mismas palabras del Concilio Vaticano II, al afirmar que el estado religioso imita más de cerca y representa perpetuamente en la Iglesia la forma de vida que el Hijo de Dios escogió al venir al mundo, para cumplir la voluntad del Padre.

A través de su existencia, los religiosos son una manifestación representativa de Cristo, entregado al cumplimiento de su misión y siempre obediente a la voluntad del Padre que le envió, bajo la modalidad que propuso a los discípulos que quisieran seguirle (Juan Pablo II, 1996: n. 22). Por medio de la obediencia, el religioso habita en un espacio en forma de muerte, que sin embargo, le lleva a adoptar una vida más íntima con Dios. Como consecuencia, participa de su amistad y pregusta aquí lo que será la vida de gracia futura, lugar privilegiado de la Pascua, de donde brota el modo nuevo de vivir en libertad (Ga 5,1). Ésta consiste en afirmar la propia condición, recordar quién se es y responder conscientemente a lo recibido, hasta dejarse vencer por el amor, fuente de salvación.

Esta delimitación de espacio, es un camino hacia la verdadera vida, que anuncia y anticipa proféticamente la posibilidad, ofrecida a cada persona, de vivir únicamente para Dios, en Cristo Jesús. Porque la muerte es el acto supremo del hombre en el que toda su vida precedente es recogida en la decisión última de su libertad y en el que la eternidad del hombre alcanza su madurez. Por eso, aunque la renuncia acompañe a veces a la manifestación externa de la obediencia, no es su objetivo, es simplemente una de sus consecuencias.

La obediencia es un acto racional, fruto de la libertad y de la autonomía personal, que transforma los mandatos en propuestas interiorizadas, para dejar que sean leyes externas y se conviertan en algo que forma parte de la propia existencia. Con la apertura al descentramiento y a la búsqueda de la voluntad de Dios, desde el desapego, persigue la dinámica del amor, que conduce hasta la inhabilitación mutua del uno en el otro. Es la paradoja que preside la sabiduría de la fe, apoyada en una plenitud que se logra, no en la búsqueda de uno mismo, sino en la respuesta a la llamada de Dios, 
manifestada excelentemente en Cristo Jesús: «el que encuentre su vida, la perderá; y el que pierda su vida por mí, la encontrará» (Mt 11,39).

Es un profetismo que proclama la elevación del Reino de Dios sobre todo lo terreno, cuando brota de una búsqueda apasionada y constante de la voluntad divina, denuncia todo aquello que la contradice y escudriña nuevos caminos de actuación del Evangelio, para la construcción de dicho reino. Este último aparece como un poder en estado de ejercicio y una acción de Dios, que conduce al hombre hacia su definitiva realización y ejerce simultáneamente su dinamismo en la humanidad entera. Su dimensión escatológica presenta una fase terrena, que se extiende desde la muerte y resurrección de Cristo, hasta su definitiva venida al final de los tiempos. En ella se proclama la provisionalidad de las realidades terrenas y la presencia de los bienes celestiales ya en este mundo. Al mismo tiempo, se prefigura la futura resurrección, como la ley a la que se subordina y orienta la ley de la creación.

\subsection{Hacia una nueva creación}

En consonancia con este contexto, la obediencia se transforma en un servicio a la plenitud de la creación, fomentando la transformación positiva de la Iglesia y el mundo, liberándolos de todo lo que los desfigura y permitiendo la participación de la resurrección de Jesús, en su transfiguración y en el envío del Espíritu. Es una aceptación de la existencia limitada y un signo de relativización de toda realidad humana que pretenda ser absoluta, apuntando constantemente a los valores supremos del reino, que siempre están más allá de las meras realizaciones humanas y permiten fecundar la historia. Porque, como nos dice Heb 13,14: «no tenemos aquí abajo ciudad permanente, sino que buscamos la futura».

En concreto, la vida consagrada está configurada como forma de vida en obediencia a la alianza con Dios $y$, desde Él, con toda la humanidad y con la creación. Participa así de un gran movimiento, que más allá de las normas, permite descubrir un plan de Dios, que se ofrece para ser cumplido y actuado (Ef. 1,11; 3,11). Es un gesto de esperanza por el que el religioso se entrega y se introduce en el futuro ofrecido por la promesa, situado en la base de la alianza de Dios con su pueblo, transformando todos sus valores personales en servicio, en donación y en carisma para los demás (Rey García Paredes, 2002: 403). Es la actuación según las pautas de una pasión, que aviva la interioridad del hombre, provocando la liberación de sus energías interiores, dando cauce y expresión a sus sentimientos más profundos y facilitando el desarrollo 
de su actividad creadora y el cumplimiento de sus sueños. Porque quien está apasionado por Dios, no sólo obedece desde su más profunda interioridad, sino que además él mismo es obediencia.

De este modo la economía de la redención transfiere el poder del misterio pascual al terreno de la humanidad, haciendo del religioso un símbolo existencial, a través de su ser carismático. Como el de cualquier otra forma de vida, constituye en sí un estilo de ser en dinamismo, originado por la presencia creativa del Espíritu.

La obediencia se transforma en una ley esencial de salvación, que introduce al hombre en la dinámica de Cristo, lo identifica con Él y lo une más a Él, adentrándose en la verdadera tierra y dejando atrás el espacio caótico del pecado. De esta forma logrará ver cumplida así la promesa: «dichosos los que lavan sus vestidos, para tener derecho al árbol de la vida y entrar en la ciudad por las puertas» (Ap 22,14). Es la clave interpretativa del sentido de la historia de cada uno y de la humanidad, que recuerda al hombre, que el retorno a su fundamento está compuesto de obediencia y que el sendero de la vida se recorre con pasos guiados por la voluntad del Creador. La obediencia se abre a la sorpresa y a lo inesperado, fruto de quien se abandona en las manos de Dios, pero al mismo tiempo, no pierde de vista al orden y lo esperado, como uno de sus privilegiados fundamentos. En efecto, enseña a leer los hechos concretos, trazando una ruta que anticipa proféticamente el futuro y que se mueve entre la contradicción y el inconformismo, cuando percibe a su alrededor, la imperfección de lo que le rodea y su llamada a conquistar la plenitud.

El religioso no sólo ha de vivir totalmente consagrado a Dios e imprimir en la tierra a Cristo, quien es el criterio, la crítica y el rostro concreto de la trascendencia. Además ha de encarnar y manifestar la espera ansiosa, colectiva y operante de una salida para el mundo, como la función cristiana por excelencia, sobrepasando todos los condicionamientos temporales (Chittister, 1998: 211). Para ello interpreta y remite más allá del tiempo, recordando que la historia de la humanidad y del cosmos es de una liberación, que aguarda la consumación. Ésta se abre a un nuevo horizonte, connotado por la encarnación siempre nueva del Evangelio de Cristo. Viviendo ya desde ahora lo más plenamente posible aquel escatológico estar ya con Cristo en Dios, del que habla San Pablo: «Si habéis resucitado con Cristo, buscad las cosas de arriba, donde está Cristo sentado a la diestra de Dios. Aspirad a las cosas de arriba, no a las de la tierra. Porque habéis muerto, y vuestra vida está oculta con Cristo en Dios. Cuando aparezca Cristo, vida nuestra, entonces también vosotros apareceréis gloriosos con él» (Col 3,1-4). 
De este modo, testifica desde su mismo ser, que el hombre está llamado a esta autotrascendencia absoluta de su persona, de la comunidad y de la historia humana en el misterio. Se trata de ser experiencia de Dios, testigo de Jesús en el mundo de hoy y anticipación de su reino en obediencia a la misión divina. Por eso, su importancia no radica en la forma de vida a la que compromete, ni tampoco en qué contenido, sino en el comprometerse a ser en obediencia, que se va traduciendo en una forma concreta, histórica y temporal de vida (Díez Presa, 1984: 58).

Se origina así una nueva creación, bajo la inscripción, en lo más íntimo de sí mismo, de la invitación a responder y servir libremente al diseño de Dios, que es Cristo. Se deja evangelizar, conquistar y animar por Él y por su misterio, cooperando eficazmente a su misión. Así contribuye con ímpetu a la renovación del mundo, como memoria evangélica de un Pueblo de Dios, que busca y camina hacia la ciudad futura. La acumulación de deseos desemboca en el estallido de la parusía ante el hombre-tiempo, cuya vida se reduce a una simple duración; del hombre-pueblo, el cual se halla en comunicación con otros, con los que comparte un destino y una búsqueda; del hombre-tierra, quien contempla al mundo en cuanto templo, desde el que establece su relación, tanto con Dios, como con sus semejantes; del hombre-historia, consciente de que con sus actos es responsable del presente y del futuro y no sólo heredero de un pasado (Clément, 1983: 158).

\section{La obediencia como contemplación del misterio de Cristo desde la oración y la vida}

Precisamente, la unidad de vida espiritual, a la que el religioso está llamado a tender, enraíza con nuestro epígrafe previo, al demostrar, que no puede realizarse más que en la persona de Cristo, descubierta y contemplada por igual en la oración y la vida. De nuevo se resalta la primordialidad de la ley cristiforme en la vida religiosa, esta vez como el eje, en torno al cual, gira la unificación de la propia vida, que encuentra cauces de expresión en la Sagrada Escritura y la liturgia.

En orden a evitar una errónea interpretación sobre la donación total a Dios y la renuncia al mundo, que convierta a esta última en un freno para la misión, el religioso ha de buscar ante todo y únicamente a Dios. Pero el hombre, para llevar a cabo este empeño interpretativo, precisa de una doble fundamentación, que conexiona la contemplación, por la que se une a Dios con la mente y corazón, y el amor apostólico, por el que se esfuerza en asociarse a la obra de la redención y a la dilatación del reino 
de Dios (Concilio Vaticano II, 1965a: n. 2). Consiste en encarnar la vida apostólica, mediante la consecución de una vida religiosa cualificada por una contemplación, que fructifica en una acción apostólica. En palabras conciliares se traduce en vivir y representar el misterio de Cristo, en su totalidad contemplativa y apostólica, configurando apostólicamente la vida contemplativa o siendo apóstol contemplativamente (Concilio Vaticano II, 1965a: n. 8). Un vivir para Dios que comporta un servicio desinteresado al hombre en el espacio y por medio de la Iglesia.

A través de la contemplación, la vida del religioso se convierte en la expresión viva del deseo de una concretización histórica del reino de Dios, gracias a una profunda comunión de sentimientos con Él, que señala el deseo de vivir a Jesús, como Él vivió a su Padre. Este vivir de Jesús brota de su oración, como espacio real que contiene la transfiguración, la cual constituye en sí la revelación del Padre y la gloria del Hijo. En su brusco descendimiento hacia la realidad cotidiana, los discípulos son invitados a vivir las exigencias del designio divino y a emprender con valor el camino de la cruz. De este modo, glorifican a Dios, mediante una actitud de continua adoración de su presencia misteriosa en las personas, en los acontecimientos y en las cosas.

Por eso, la oración no implica una separación de la realidad, sino que por el contrario, se identifica con una dimensión trascendente del ser histórico, que alimenta su vida de fe. A través de ella, Dios aumenta en el hombre el deseo de ser colmado por Él, ensanchando así su alma, para hacerle capaz de recibir la gran realidad que se le entrega; Él mismo (Benedicto XVI, 2007: n. 33). El hombre se introduce así en un proceso de purificación interior, caracterizado por una unión personal con Dios, a través de la misma acción, expresión dinámica y forma existencial de la oración. Como dice el Evangelista San Juan: «vosotros sois mis amigos, si hacéis lo que yo os mando» (Jn 15,14). La intensidad de la oración sirve de barómetro para medir la dignidad de la vida. Al mismo tiempo, la forma de vivir revela la calidad de la oración, la cual se expresa y perfecciona a través de la vida.

Al igual que el hombre no puede alcanzar la santificación o la salvación, por sí mismo, el apostolado, es pasión y acción de Dios a través de la propia acción humana, recordando que sólo Dios es quien salva y santifica. Cuando el religioso actúa desprovisto de la experiencia de Dios, falsifica su propia vida. Abandona su intrínseca condición de místico, profundamente arraigada en su existencia como consagrado, disminuye su potencialidad ante el compromiso por la humanidad y pierde su capacitación para incidir mejor en la historia y liberarla de todo lo que la desfigura (Juan Pablo II, 1996: n. 75). Respecto a este último aspecto, la obediencia se convierte en el testimonio de unos valores que 
desafían tanto a la sociedad, como a los religiosos. Los introducen en una auténtica contradicción, que adopta la forma de una profecía en acción del reino futuro y guía hacia una renovación salvífica. Como se nos dice en $\mathrm{Rm} \mathrm{12,2:} \mathrm{«no} \mathrm{os} \mathrm{conforméis} \mathrm{a} \mathrm{este} \mathrm{siglo,} \mathrm{sino} \mathrm{que} \mathrm{os}$ transforméis por la renovación de la mente, para que sepáis discernir cuál es la voluntad de Dios, buena, grata y perfecta».

Partiendo tanto del sustento teológico que configura a la vida religiosa, como una consagración total e inmediata de amor a Dios en la Iglesia y para la Iglesia y un signo en la misma, de la presencia de la vida de Cristo, virgen, pobre y obediente, como de la observación de su concretización práctica, se obtiene su configuración esencialmente apostólica. Pero la misión primaria y fundamental de la vida religiosa, no se reduce a un simple hacer pragmático, o sea, a la realización de un conjunto de actividades en favor de los demás, implica la consagración, es decir, el ser mismo de la vida religiosa, entendido en su sentido más dinámico. Mientras que «la ocupación requiere sólo determinados momentos, la misión precisa de todo el tiempo» (González Silva, 1985: 104). Porque la misión no es algo sobreañadido a la propia identidad, sino la misma identidad en su sentido operativo, hasta el punto de que sin identidad, no puede haber misión y sin misión, la identidad se desvanece.

Toda forma de vida religiosa, incluso la específicamente contemplativa, no se repliega sobre sí misma, sino que se convierte en testimonio profético de su orientación al Padre por el amor, tratando de responder a los interrogantes del ser humano sobre el sentido de la vida presente y futura y su posible relación (Juan Pablo II, 1996: n. 73). Las diversas manifestaciones misionales son preparaciones y profecías de la única misión del Pueblo de Dios, que constituye, en cierta manera, el núcleo de todo el misterio eclesial. Se fundamenta en la consagración del Hijo, por obra del Padre. En su envío al mundo como mediador entre Dios y los hombres. En el envío del Espíritu, desde el Padre y por parte de Cristo, para que realizara su obra santificadora desde dentro y provocara de ese modo el crecimiento de la Iglesia.

La profundización en la naturaleza de la acción apostólica, revela su condición de constituir una fuente de unión con Dios. Conduce al religioso a santificar sus actividades hasta convertirlas en fuente de comunión con Él, así como a percibir la riqueza santificante contenida en todo ministerio eclesial. Su consagración posibilita y compromete al religioso en la obra divina, llamado a realizarla bajo su condición de enviado y con el poder de Dios. Si la obediencia es vivir apasionados por la voluntad del Padre, al igual que vivió el Hijo, el religioso no es un simple instrumento pasivo de Dios en la obra de su salvación. Por el 
contrario, su propia libertad es una autollamada a ser el máximo colaborador de Dios en el proceso de llevarse a sí mismo y a su historia a la plenitud. De este modo, se convierte en una prolongación de la misión del mismo Cristo en la historia del mundo, compartiendo la obediencia de Aquel que se ofreció al Padre por la vida del mundo (Juan Pablo II, 1996: n. 25).

El religioso comparte la obra salvadora de Cristo, a través de determinados servicios que requieren tanto capacitación, como una aprobación de la Iglesia. Ésta, no sólo asume la naturaleza del servicio emprendido, sino que a la vez, refuerza y delimita la misión del religioso. Así determina cómo la misión ha de ser realizada, en unión profunda con el Señor y con una gran sensibilidad respecto a los tiempos. Su trabajo de evangelización, que tenderá a transformar la humanidad desde dentro, encuentra su fuente en la obediencia religiosa, la cual lo mantiene atento a las esperanzas de los hombres, determinando así la identidad misma de la vida consagrada. Sin olvidar que la fe sin obediencia es una fe muerta y la obediencia sin fe es un simple comportamiento social. En cambio, la obediencia de la fe, es presentada como obediencia del hijo y servidor, como exigencia y camino de autenticidad, de donar la propia vida, confiando libre y totalmente a Dios, prestando «a Dios revelador el homenaje del entendimiento y de la voluntad, y asintiendo voluntariamente a la revelación hecha por El» (Concilio Vaticano II, 1965c: n. 5).

\section{La obediencia: una referencia al pasado, una respuesta al presente y una apertura al futuro}

Más allá que un inamovible apego a la tradición y a su pasado, la obediencia se convierte en la respuesta a las necesidades del presente. Fiel a las inspiraciones del carisma, refleja el dinamismo de la historia y de cada ser humano, los cuales, participan de la encarnación redentora, en su aspiración por alcanzar la futura unión con Dios.

\subsection{La vida religiosa como expresión del anhelo por la belleza divina}

La misión de la historia no consiste sólo en la construcción de su propio futuro, sino implica también una conmemoración y anuncio, que revive la primera venida del Señor y prepara la parusía o venida al final de los tiempos. El móvil de todo este recorrido viene trazado por la esperanza, la cual permite que el hombre no sea prisionero del presente o 
del pasado y no se preocupe de su propio éxito. Al contrario, lo aproxima al universo, como una escritura viva que Dios traza incesantemente ante sus ojos y sobre la que Cristo domina como el punto de partida y de llegada, en el que todo encontrará su perfección y cumplimiento. Dentro de este contexto se ubica la vida religiosa, como una de aquellas palabras que permiten advertir la fascinación y nostalgia por la belleza divina (Juan Pablo II, 1996: n. 19). Ésta encuentra una de sus visualizaciones en el empeño de cada consagrado por focalizar su atención en el amor a Jesús, en la contemplación del Crucificado y en la espera de la resurrección, como la perspectiva de vida más auténtica, que trasciende la muerte.

Con independencia de su modalidad concreta, toda Orden no sólo se halla insertada en este dinamismo de creación continua, que presenta momentos de mayor o menor intensidad, sino que además no existe para sí, ni subsiste por sí misma, ni consiste en sí misma. En efecto, encarna una forma de vida, que como cualquier otra, no se define por sí misma, sino que es una variante utópica de la humana. Ésta no encuentra su absoluta definición, sino que recibe su existencia, como necesidad de acallar el desconcierto que provoca el misterio de una vida sin adjetivos. Rechaza toda reclusión en la propia especificidad, para indicar la amplitud del fenómeno vital y asumir la vida de un modo peculiar, partiendo de la unidad diferenciada y seminal, para pasar por la totalidad de las diferencias y llegar a la unidad de la comunión total.

En este caso la vida religiosa es una célula viva que contiene en sí todo el misterio vital del cuerpo único de la Iglesia, enriqueciéndola con sus propias características, en conformidad con su espíritu peculiar y su misión específica. Nace en y para la Iglesia, de su vitalidad intrínseca y pertenece a su estructura pneumática y carismática, como una radiografía de la misma, que simboliza existencialmente la esperanza mesiánica y expresa visible y socialmente la santidad eclesial. Impulsada por este objetivo, recuerda las intervenciones salvadoras de Dios en el pasado y exhorta a la conversión desde la presente infidelidad a Dios, viviendo con ejemplaridad la radicalidad de la fe cristiana. Un memorial sobre el que se construye la Iglesia, adornada por la inquietud y la agilidad de su propia estabilidad. De este modo se convierte en un factor contribuyente a que la Iglesia sea una escuela, donde se eduquen hombres capaces de hacer historia (Congregación para los Institutos de vida consagrada y las Sociedades de vida apostólica, 2002: n. 28).

Como ya indicamos, su carisma específico consiste en tematizar la experiencia de Dios en Jesucristo y hacer de ella el proyecto fundamental de toda la vida y el eje de toda referencia. Como todo carisma, encierra en sí el todo en el fragmento, debiendo reflejar en la totalidad del mismo 
Cristo, una serie de valores clave: la referencia a su vida y misión, en general o en alguna de sus particularidades. Su generación por el Espíritu, como interpretación vital de una serie de valores evangélicos, claramente discernidos en su origen y sellados por el reconocimiento eclesial. Una particular vivencia eclesial, de su apostolado y misión, que la conducen a la eclesialización de la misión, es decir, hacia la humanidad, término de la misión trinitaria. Una síntesis de humanización y una esperanza activa, basada en la experiencia y en el continuo recordar en qué consiste el seguimiento radical de Jesús. Todo ello, a través de los valores que nos trasmite la pedagogía del carisma, capaz de realizar al hombre nuevo en la medida de Cristo.

En particular, los consejos evangélicos son una concretización histórica de la identidad de la vida religiosa, como forma de vida cristiana. Es decir, son un componente esencial de la vida religiosa, identificada con un movimiento hacia el reino de Dios. Ésta vive radicalmente y promueve a través de su acción apostólica algunos de los valores del mismo, hasta indicar que es posible un mundo nuevo para todo el Pueblo de Dios. Es el gozo de lo que existe y el parto de lo que va a existir, que actualiza la intervención de Dios en la historia. No como lo puramente acaecido, sino también como una profecía de lo que va a suceder, insertándose como el alimento de la paciencia histórica, entre la primera y segunda venida de Jesús. En definitiva, los consejos evangélicos, son la radicalización de la vida evangélica en sus más profundas exigencias. Un modo particular de participar en la naturaleza sacramental del Pueblo de Dios, indicándole lo que está llamado a ser en la línea de la santidad y del seguimiento de Cristo. Todo hasta la plena conformación con Él y, por tanto, en la definitiva participación al misterio de la vida divina.

\subsection{El carisma como una participación en la encarnación redentora}

La historia demuestra que todos los fundadores de nuevas formas de vida religiosa, fueron profetas, que partieron de la proyección de luz que el Espíritu aporta sobre los acontecimientos, interpretándolos como señales de los tiempos y leyendo en la trama de los sucesos, el designio de Dios (Ciardi, 1996: 125). Su fundación, surgió tan sólo después, como fruto de la experiencia que vivieron previamente y que transmitieron a sus primeros discípulos, inaugurando un nuevo camino hacia Dios y una modalidad de experiencia espiritual. No se limitaron a enunciar los hechos, a modo de crónica, sino a hacer historia, partiendo de la fidelidad a la alianza y de su consecuente referencia al pasado. Penetraron 
en la realidad de su tiempo, para asumirla e infundirle la dimensión crítica y evangélica de transformación, por medio de su capacidad de guiar hacia el futuro prometido por Dios. Por eso, no interpretaron el pasado exclusivamente desde su dimensión temporal, sino desde el ideal paradigmático que contiene, actuando no según los hechos, sino según la modalidad de percepción del hecho, que tiene lugar en una visión de fe.

El nacimiento y existencia de una nueva institución suele provocar fuertes oposiciones contra ella, porque en cierto modo, turba una cómoda forma de vida, proponiendo las exigencias radicales del Evangelio y desbaratando cuadros ya establecidos a los que el hombre se habitúa. Pero la profunda comprensión de esta especificidad del carisma conduce a una visión clara de la propia identidad, de creciente configuración con Cristo. Ésta se va realizando en conformidad con el carisma y normas del instituto al que el religioso pertenece, los cuales determinan su propio espíritu, carácter, finalidad y tradición. El carisma es un reflejo y una participación particular de la encarnación redentora, que al mismo tiempo, indica la distancia que separa al hombre y a la Iglesia, de la verdad evangélica. En efecto, su imposibilidad de realizarse perfectamente en el camino histórico, los exhorta a un constante retorno a los orígenes, a no alejarse de la genuinidad de su ser y a permanecer firmes en su identidad.

A través de la obediencia el religioso orienta toda su vida hacia la consecución de la unión con Dios, fin al que todo hombre está llamado a tender y cuya aproximación se realiza en consonancia con la diversidad de carismas que entretejen la gran familia eclesial. De este modo, el carisma de cada instituto se convierte en la modalidad con la que cada uno de sus miembros, se esfuerza por unirse a Dios, dando así significado a la totalidad de su vida y respondiendo a las necesidades de su entorno (Sagrada Congregación para los Religiosos e Institutos seculares y la Sagrada Congregación para los Obispos, 1978: n. 11).

Es preciso no perder de vista su condición de diferenciaciones funcionales dentro de un grupo con una misión común. Sólo desde su unidad surge el verdadero ser del carisma total de la vida religiosa en la Iglesia. Dentro de éste, cada instituto es una parte cualitativa, con una peculiar misión carismática, la cual, como ya vimos, no se confunde o identifica con sus obras, aunque sean una forma especial de expresarla y actuarla. No se trata del esfuerzo por obtener algo exterior al carisma, sino de cómo construir interna o sustancialmente la misma vida de la familia religiosa, cuya diversidad de prácticas cualifica el fin al que se dirigen. 


\subsection{El carisma: una realidad viviente}

La sacralidad de la historia se manifiesta en la existencia de toda Orden religiosa. Ésta, como cualquier organismo vivo, no acaba nunca de ser ella misma, sino que se sumerge en todo un proceso de superación, que invita a distinguir entre sus propias vicisitudes históricas, generadas por su condición de peculiar forma, y la misión eclesial de la vida consagrada como tal. Al mismo tiempo, al mostrar una actualización nueva del mensaje de Cristo, en consonancia con las nuevas exigencias, recuerda a la Iglesia la necesidad de una constante actualización de aquellos orígenes a los que debe permanecer fiel en las situaciones del tiempo en que vive y que varían continuamente. Impide así que se estanque en posiciones preestablecidas y que se anquilose en un pasado que traiciona los orígenes (Juan Pablo II, 1996: n. 63).

No sería legible el Evangelio al margen de la situación vital de los receptores y de un presente, que aunque sea fatigoso, se puede vivir y aceptar si lleva hacia una meta, tan grande, que justifique el esfuerzo del camino. Porque el dinamismo de la necesidad humana transforma la realidad en su propio provecho o en vistas a la supervivencia. Pero a veces las circunstancias originan una evolución lenta, que sucumbe ante las pretensiones de mantener la propia identidad de la Orden, hasta dar lugar a un cambio de rostro.

En ocasiones resulta patente la existencia de un desfase del instituto, que se aferra a una fidelidad literal a sus orígenes, con respecto a una sociedad ambiente, insertada en una continua evolución. En efecto, el conjunto de todos los accidentes es necesario, en cuanto señala y posibilita modos y formas concretas de realizar las cosas en su contexto determinado. Esto quiere decir que nada puede sustituirse sin saber antes qué aspectos de la realidad sustancial están expresados, contenidos y clarificados en ellos. E igualmente, sin estar en condiciones de suscitarlos por otros, que expresen en un contexto diferente, la misma realidad que antes era vivida. Conviene recordar esta realidad, cuando hablamos de tradiciones, las cuales no son sino realizaciones concretas de la tradición suprema de cada instituto. Difieren entre sí, no sólo en cuanto a su contenido, sino también respecto a su mutabilidad o permanencia, según el grado de vinculación, que tengan con el carisma original.

Muchas de las dificultades del presente, residen en una falta de comunión con el carisma y en una excesiva concentración y pérdida de tiempo en cuestiones externas, que siendo accesorias pasan a ocupar un puesto de honor, a la dejadez y olvido de la raíz originaria, o incluso a una vivencia monótona de la misma. Es necesario volver cada día sobre nuestras raíces, para poder atrapar cada vez mejor el escurridizo e 
imprevisible futuro y sobre todo, para responder a las exigencias de nuestro presente. Sólo así el consagrado vivirá en obediencia, es decir, será fiel a su identidad de criatura, configurada como reproducción y prolongación de un rasgo distintivo de Jesús y con él, de toda su persona.

El hombre espera, dirige su futuro y lo planifica, exponiéndose a cada paso a la imprevisibilidad. La diferencia entre lo que es y lo que está llamado a ser es el principio dinámico del desarrollo histórico, que mantiene abierta la expectativa del fin (De Sahagún Lucas, 1996: 35). Toda época humana tiene una relación con su pasado. Sus visiones e impulsos o bien surgen dialécticamente de la superación y ruptura crítica de los anteriores, o de un intento de restauración de la tradición, bajo la nueva óptica de su presente. El significado de la historia recibe el impacto directo de su crítica. Porque el pasado, por glorioso que fuera, nunca asienta sus bases entre las futuras generaciones, ya que por bueno que fuese en su momento, no justifica su permanencia cuando todas las circunstancias han cambiado.

Cabe la posibilidad de aferrarse a lo pasado como definitivo, sin querer reconocer en él las limitaciones de todo lo humano, histórico y perecedero. Sin caer en la cuenta de que las propias raíces se encuentran en los eventos salvíficos del pasado y no en los productos históricos que fueron interpretaciones de estos eventos, válidos para aquella época. Es necesario tomar conciencia de que nada existe ni por sí ni para sí, sino que pertenece al conjunto que engloba todo lo que existió, existe y existirá. Existe gracias a lo que fue y es y existe para lo que es y será. Para evitar excesivos estragos, habría que señalar y potenciar que todo lo que existe tiende siempre hacia un mismo fin, que es la unión con Dios. Y el hombre se dirige hacia el mismo, por la nostalgia que genera el reconocer que existe un más, una mejora de lo que él es en sí mismo. Esta zozobra e inquietud le revela su deseo de belleza y de plenitud, apoyado no en la fantasía sino en el conocimiento histórico y, más aún, en aquello que le resulta más próximo a su tiempo y a su realidad personal. Porque dicho conocimiento no es un simple conjunto de conocimientos intelectuales, sino un saber que porque es tal, sirve, se expresa y recobra vida diariamente en cada uno de sus pasos y de sus coetáneos.

Es preciso tener en cuenta, que ya que el carisma es más extenso que sus personas, es necesario ser más fieles al Espíritu que a la persona del fundador. En definitiva, la auténtica fidelidad al pasado, implica una fidelidad dinámica al presente y al futuro, dada su pretensión de responder a las necesidades y aspiraciones de los hombres de todos los tiempos y lugares. La crítica constructiva no supone un desprecio al pasado, sino la condición indispensable para descubrir la clave, que partiendo del conocimiento del mismo, permita situarse en el presente, 
sin repetir los errores de otro tiempo. Basta pensar en las palabras de $\mathrm{Mt}$ 5,20: «porque yo os digo que si vuestra justicia no supera la de los maestros de la ley y la de los fariseos, no entraréis en el Reino de Dios». De este modo, la fidelidad a Dios exige la fidelidad a los hombres. Es la respuesta a una obediencia, que alcanza su plena realización, cuando es interpretada como el espíritu de grandes iniciativas desde la fidelidad, docilidad y generosidad a las inspiraciones, que surgen a consecuencia de las exigencias del carisma y de la escucha del clamor del pueblo.

\subsection{La obediencia a la fe como encarnación en la realidad}

La originalidad del mensaje cristiano no consiste directamente en la afirmación de la necesidad de un cambio de estructuras, sino en la insistencia en la conversión del hombre, que exige luego este cambio. Realizando una mirada a las diversas formas de vida religiosa, descubrimos cómo el estado religioso y su búsqueda de Dios, son dos dimensiones que están llamadas a compenetrarse. Convierten a los esfuerzos realizados por los institutos, no en una cadena de adaptaciones, determinadas por los cambios del mundo. Por el contrario, en el descubrimiento fecundo de los medios indispensables, para conducir una existencia penetrada por el amor de Dios y de los hombres.

Más allá de las distintas formas de vida inherentes a la existencia cristiana, como por ejemplo, la vida religiosa, destaca la obediencia a la fe. Ésta presenta a la santificación propia y la del prójimo, como un solo, idéntico y único fin, que constituye la misma trama de su consagración, encarnada, vivida y expresada en su acción (Juan Pablo II, 1996: n. 35). No se caracteriza simplemente por una actitud generosa, sino por un proyecto de vida, que encuentra su inspiración primordial y su finalidad última en la comunión con la obediencia de Jesús al Padre. Dicha obediencia permite que la Palabra y la Promesa se encarnen en la realidad. Configura al cristiano a semejanza de Dios, invistiéndole de una responsabilidad de salvación, asociada a la consumación cualitativa e histórica de la obra para la que Jesús fue enviado.

El motivo por el que el religioso imita la vida humana de Cristo, supera todo interés arqueológico. Se adentra en la misión redentora o plan de salvación, como bien común, que se manifiesta hasta en la propia estructura existencial humana de los consejos evangélicos.

La carencia de un descubrimiento de su significación universal, recibida de la resurrección de Jesús, convierte a la fe cristiana en un recuerdo del pasado, a los sacramentos en mera nostalgia de los gestos de Jesús y al seguimiento en un recuerdo imaginario de los caminos desde Galilea hasta Jerusalén. Por el contrario, la renovación de los 
medios y de sus formas de actuación, a través de los que se expresa el carisma de un instituto religioso, han de adaptar las prescripciones del fundador, a las circunstancias concretas de la vida actual. En consonancia con las cuatro grandes fidelidades de las que nos habla el Concilio Vaticano II; a la humanidad y a nuestro tiempo, a Cristo y al Evangelio, a la Iglesia y a su misión en el mundo y a la vida religiosa y al carisma del instituto (Concilio Vaticano II, 1965 a: n. 2).

Precisamente la libertad humana se motiva y se justifica en virtud de un fundamento que está más allá de ella misma (Concilio Vaticano II, 1965b: n. 17) y se identifica con Dios, como una exigencia que se impone y una realidad original de la que todo fluye. Se trata de la verdad personificada en el Hijo, en quien la divinidad y la humanidad se integran profundamente, hasta convertir su abandono al Padre en la modalidad humana de participación en la fuerza del amor de Dios. Como nos dice el Evangelista San Juan: «Si permanecéis fieles a mi palabra, seréis de verdad discípulos míos, conoceréis la verdad y la verdad os hará libres [...] Si el Hijo os hace libres, seréis realmente libres» (Jn 8, 32.36). Cuando se acoge al Hijo como el rostro histórico y personal de la libertad divina, la voluntad humana asume el rostro de la fe. Es decir, se identifica con una libertad que llega a reconocer a Dios y, que entendida como bien salvífico, es la obra del Espíritu y el criterio de una profunda renovación de la criatura.

En el centro de la identidad personal se sitúa la acción de aquel sí mismo, que es el único capaz de asegurar históricamente estabilidad a la vida del individuo. Esto se realiza a través de la capacidad recibida para integrar las formas múltiples de la vida y de la referencia a un principio último, que dé fundamento a la continuidad de la persona. El límite que se impone ante el alcance de la propia identidad, no viene determinado por la naturaleza, sino por el empeño humano por vivir de modo finito el amor infinito de Dios. Esta restricción produce el declive de la antropología del hombre nuevo, introduciéndolo en el afán histórico de la humanidad en devenir.

El desafío de una seria experiencia de Dios y de una pasión misionera, se manifiestan hoy como conversión al Dios vivo, cuya sed alimenta el éxodo del hombre y su misión da sentido e identidad a la vocación cristiana y en particular a la del consagrado. Por lo mismo se debe aceptar que las nuevas experiencias y formas de espiritualidad no son sólo frutos de una búsqueda humana, sino verdaderas llamadas y desafíos del Espíritu para una sociedad y una humanidad que no encuentran los caminos de la trascendencia y que buscan con afán el misterioso rostro de Dios. 
En este contexto, la obediencia se define a sí misma, no sólo como una condición y exigencia del orden familiar y social, sino también como una condición de la koinonia del ministerio de la salvación sobrenatural. Éste trata de responder a la manera de ser del hombre y a la naturaleza misma de la vida trinitaria, que es la que se comunica al hombre en la salvación.

\section{La obediencia:}

\section{la convergencia de las voluntades hacia un único Dios}

La obediencia es la base de la vida fraterna, que permite a cada miembro el encontrarse consigo mismo y con Dios. De este modo, unifica a todos en Dios y convierte a la comunidad en un apostolado y un objeto de contemplación.

La comunidad religiosa es una especie de condensado expresivo de la Iglesia, que le recuerda su más profunda razón de ser: seguir a Cristo de modo libre y radical. Con el objetivo de gozar de su presencia, compartir su camino pascual y alcanzar a través de Él la intimidad con el Padre, para ponerse después con Él al servicio de la humanidad y vincular a todos en el Cuerpo de Cristo. Al mismo tiempo, proclama el amor recíproco entre las divinas personas en la Trinidad, como el modelo y propuesta concreta de vida espiritual (Juan Pablo II, 1996: n. 41). También a Jesús, en su misterio pascual, como la fuente, el modelo y la medida, de cómo se construye la unidad, viviendo el vaciamiento de cada uno, hasta el don total de sí y llegar a ser uno. Porque el religioso no es sólo un llamado con una vocación individual, sino que es un convocado. Un llamado junto con otros, con los cuales comparte la existencia cotidiana y su profesión religiosa como expresión del don de sí mismo a Dios y a la Iglesia.

El móvil de actuación de la comunidad religiosa es el amor, el cual engloba la existencia entera y en todas sus dimensiones, incluido también el tiempo, puesto que su promesa apunta a lo definitivo, interpretado tanto como exclusividad, como en el sentido del «para siempre». Nunca es completado, sino que se transforma en el curso de la vida, reconociendo su propia vía en el reconocimiento del Dios viviente y madurando en el progresivo sí de la voluntad humana a la divina y, precisamente por ello, permanece fiel a sí mismo. Es un salir del yo cerrado en sí mismo, hacia la liberación, a través de su propia entrega, mediante un camino permanente, que conduce hacia el reencuentro consigo mismo y hacia el descubrimiento de Dios: «el que pretenda guardarse su vida, la perderá; y el que la pierda, la recobrará» $(\operatorname{Lc} 17,33)$. 
Con estas palabras, Jesús refleja su propio itinerario, que a través de la cruz lo lleva a la resurrección, partiendo de su sacrificio personal y de su correspondiente expresión del amor en plenitud, para describir la esencia del mismo y de la existencia humana en general.

La cruz de Cristo ofrece al consagrado, de un modo pleno y definitivo, dos certezas fundamentales: la de ser amado infinitamente y la de poder amar sin límites. Identifica su vida con una participación en la caridad de Cristo, en su amor al Padre y a los hombres, gracias a los cuales se libera progresivamente de la necesidad de colocarse en el centro de todo, de poseer al otro y del miedo a darse a él (Pablo VI, 1971: n. 29). En virtud de este amor nace la comunidad como un camino de liberación, que conduce a la plena comunión y a la libertad de los hijos de Dios, exigiendo sin embargo el coraje del olvido total de sí mismo en la aceptación y acogida del otro. Porque el amor es más fuerte que la muerte, a condición de que el primero haya sido más fuerte que la vida.

La historia entre Dios y el hombre consiste precisamente en que esta comunión de voluntad crece en la comunión del pensamiento y del sentimiento en el acto único del amor. La voluntad de Dios deja de ser algo extraño para el hombre, que se impone desde fuera, hasta convertirse en su propia voluntad, experimentando que Dios está más dentro de sí, que lo más íntimo de él mismo. Es el camino de la obediencia, dispuesta a renunciar a la propia voluntad para contraer plenamente la de Dios. A ligar las diversas voluntades en una misma comunidad fraterna, que tiene una misión específica que cumplir en la Iglesia. De este modo, la obediencia conquista su plena inteligibilidad en la óptica de la unidad a la que la comunidad es llamada, como fruto de la respuesta a la común llamada y del común cumplimiento de la voluntad del Padre que en la Palabra se manifiesta, hasta alcanzar un rostro particular y una única mente.

La experiencia de la presencia de Jesús en medio a cuantos son reunidos en su nombre, es experiencia de comunión en el amor, que revela aquella unidad pedida al Padre en la oración sacerdotal, como supremo diseño de Cristo. Dicha experiencia les hace tomar conciencia de que su seguimiento a Cristo obediente, pobre y casto, sólo puede ser vivido en la fraternidad. $\mathrm{Al}$ mismo tiempo, es el componente esencial y distintivo de su forma de vida, que se convierte en signo de comunión fraterna. En concreto, por medio de la obediencia, el consagrado se libera de todo impedimento contra la caridad y se convierte comunitariamente en signo profético de la íntima unión con Dios, amado por encima de todo. Del mismo modo lo compromete a sentirse corresponsable de la vida fraterna en común, a fin de que manifieste de un modo 
claro su pertenencia a Cristo, el cual escoge y llama a hombres a vivir juntos en su nombre.

De este modo, existe una profunda compenetración y mutua implicación entre la comunión y la misión. La comunión representa la fuente y al mismo tiempo el fruto de la misión, la comunión es misionera y la misión se ordena a la comunión. Es más, la comunidad es en sí misma sagrada predicación. Sin la adecuada integración de la dinámica entre misión y vida comunitaria, las comunidades corren el riesgo de convertirse en comunidades apostólicamente muertas. La misión es emprendida como una responsabilidad comunitaria, en la que cada uno de sus miembros participa, con sus cualidades y dones, en la misión de Cristo, que la Iglesia ha encomendado al Instituto. Éste la expresa y realiza a través de las obras inspiradas por el carisma fundacional. No se limita a un programa o proyecto, sino que se trata de compartir la experiencia del acontecimiento del encuentro con Cristo, testimoniarlo y anunciarlo (Hch 1,8).

$\mathrm{Al}$ mismo tiempo que los miembros de la comunidad son enviados a predicar el Evangelio a toda criatura, son llamados a vivir unidos. Para que el mundo crea que Jesús es el enviado del Padre, al que se debe prestar la plena adhesión de la fe. En efecto, la fraternidad es el signo que demuestra el origen divino del mensaje cristiano y posee la fuerza para abrir los corazones a la fe. Ésta es el don, que hace posible el encuentro del hombre con el misterio de Dios, abandonándose en Él, sin circunscribirlo a los conceptos humanos. Ocupando por tanto, un puesto central en su experiencia religiosa, en su pensamiento y acción, en la vida comunitaria y en el apostolado.

La referencia al propio fundador y al carisma, tal como ha sido vivido y comunicado por él y después custodiado y desarrollado a lo largo de toda la historia del instituto, es un elemento fundamental para la unidad de la comunidad. Porque el carisma también abarca el modo de vivir y de organizar lo constituido, de lo que es un postulado especial la vida en común. Vivir en comunidad es en realidad vivir todos juntos la voluntad de Dios, según la orientación del don carismático que el fundador ha recibido de Dios y ha transmitido a sus discípulos y continuadores. La obediencia mutua es un elemento sin el cual no existe verdadera relación ni dimensión comunitaria. Pasa por ayudar al otro a superarse a partir de lo que es, siguiendo el camino escogido y de acuerdo con las propias capacidades, para favorecer la aparición, cada día más clara, de la imagen de Dios en Él (Juan Pablo II, 2001: n. 43).

Desde esta óptica de obediencia comunitaria a Dios, los religiosos buscan juntos el modo de vivir y servir al Evangelio, en consonancia con las circunstancias actuales y salvando la identidad de su Instituto. 
Encarnan su espiritualidad a través de la fidelidad a los orígenes, es decir al nacimiento del instituto, a la inspiración personal del Espíritu (la vocación personal) y al mundo y a la Iglesia, fuera de estas dimensiones no habría para el religioso ninguna razón de ser. Si la elección personal del consagrado, traduce una obediencia a Dios, la fidelidad a esa elección manifiesta la permanencia de esa obediencia. Ésta se concretiza en la fidelidad al Evangelio en y a través del tipo de vida elegido. Se transforma en el espacio en que se vive el mensaje de Jesús y el camino por el que se participa de su obediencia. La fidelidad al propio carisma conduce a las personas consagradas a dar un testimonio profético, que no teme arriesgar incluso la propia vida (Juan Pablo II, 1996: n. 85).

\section{Conclusión}

En definitiva, de todo lo visto hasta ahora, podemos concluir afirmando, que la obediencia es la expresión vital de la dimensión trascendental del ser humano, quien a través de la razón y la fe, se adentra en un proceso de identificación de su ser y de reencuentro con los demás. Éste encuentra su inspiración y finalidad en la vida de Jesucristo y culmina en la unión con Dios, a través de una creciente comunión del pensamiento y del sentimiento con Él, vivida dentro de una comunidad eclesial, realizada en consonancia con el propio carisma y manifestada bajo el acto único del amor. Es la identidad misma de todo ser humano, cuyo nacimiento manifiesta la esperanza de Dios en los hombres. Y se prolonga en la eternidad, a través de la voz de esa existencia, que traspasa la barrera de la muerte física, para seguir hablando, desde el corazón y la credibilidad de una vida «ya vivida».

\section{REFERENCIAS}

-Alonso, S. M (1998). Vivir en Cristo: El misterio de la existencia. Madrid: BAC.

-Benedicto XVI (2007). Carta encíclica Spe Salvi, 30 de noviembre.

-Boisvert, L. (1989). La obediencia religiosa. Santander: Sal Terrae.

-Chittister, J (1998). El fuego en estas cenizas. Espiritualidad de la vida religiosa hoy. Santander: Sal Terrae.

-Ciardi, F. (1982). I fondatori nomini dello Spirito. Per una teologia del carisma di fondatore. Roma: Cittá nuova.

-Ciardi, F. (1996). In ascolto dello Spirito. Ermeneutica del carisma dei fondatori. Roma: Cittá nuova.

-Clément, O. (1983). Sobre el hombre. Madrid: Encuentro. 
-Concilio Vaticano II (1964). Constitución Dogmática sobre la Iglesia Lumen Gentium, 21 de noviembre.

-Concilio Vaticano II (1965a). Decreto Perfectae Caritatis sobre la adecuada renovación de la vida religiosa, 28 de octubre.

-Concilio Vaticano II (1965b). Constitución pastoral Gaudium et spes, 7 de diciembre.

-Concilio Vaticano II (1965c). Constitución Dogmática Dei Verbum, 18 de noviembre.

-Congregación para los Institutos de vida consagrada y las Sociedades de vida apostólica (2002). Instrucción Caminar desde Cristo: un renovado compromiso de la vida consagrada en el tercer milenio, 19 de mayo.

-De Sahagún Lucas, J. (1996). Las dimensiones del bombre. Antropología filosófica. Salamanca: Sígueme.

-Díez Presa, M. (1984). Antropología de la vida religiosa. Madrid: Publicaciones claretianas.

-Fernández, B. (1995). El Cristo del seguimiento. Madrid: Publicaciones claretianas.

-Feuerbach, L. (1975). La esencia del cristianismo. Salamanca: Sígueme.

-González de Cardenal, O. (1975). Jesús de Nazaret. Madrid: Bac.

-González Silva, S. M. (1985). La vida religiosa apostólica. Madrid: Publicaciones claretianas.

-Juan Pablo II (1984). Exhortación apostólica Redemptionis donum, 25 de marzo.

-Juan Pablo II (1994). Carta apostólica Tertio Millennio adveniente, 10 de noviembre.

-Juan Pablo II (1996). Exhortación apostólica postsinodal Vita Consecrata, 25 de marzo.

-Juan Pablo II (2001). Carta Apostólica Novo Millenio Ineunte, 6 de enero.

-Lisboa M. De Oliveira, J. (2003). Vivir los votos en tiempos de posmodernidad. Un reto para la vida consagrada (tercera edición). Madrid: San Pablo.

-Pablo VI (1971). Exhortación apostólica Evangelica Testificatio, 29 de junio.

-Rahner, K. (1979). Curso fundamental sobre la fe. Introducción al concepto de cristianismo. Barcelona: Herder

-Rey García Paredes, J. C. (2002). Teología de la vida religiosa (Segunda Edición). Madrid: Publicaciones claretianas.

-Ruiz de la Peña, J. L. (1991). El don de Dios. Antropología teológica especial. Santander: Sal terrae.

-Sagrada Congregación para los Religiosos e Institutos seculares y la Sagrada Congregación para los Obispos (1978). Instrucción Mutuae Relationes, 14 de mayo.

-Sagrada Congregación para los Religiosos e Institutos seculares (1983). Elementos esenciales de la doctrina de la Iglesia sobre la vida religiosa dirigidos a los institutos dedicados a obras apostólicas, 31 de mayo.

Sumario: 1. La obediencia: una respuesta a la misión de autotrascendencia del ser humano; 1.1. La aceptación de la propia condición de criatura; 1.2. La llamada a unirse al Creador; 2. La existencia cristiana como obediencia a Dios y a su mediador Jesucristo; 2.1. La recapitulación de la creación en Cristo; 2.2. El 
carisma: una lectura particular del misterio de Cristo; 2.3. Hacia una nueva creación; 3. La obediencia como contemplación del misterio de Cristo desde la oración y la vida; 4. La obediencia: una referencia al pasado, una respuesta al presente y una apertura al futuro; 4.1. La vida religiosa como expresión del anhelo por la belleza divina; 4.2. El carisma como una participación en la encarnación redentora; 4.3. El carisma: una realidad viviente; 4.4. La obediencia a la fe como encarnación en la realidad; 5 . La obediencia: la convergencia de las voluntades hacia un único Dios; Conclusión; Referencias. 